\title{
APPLICATION OF THERMAL ANALYSIS IN FERROUS AND NON- FERROUS FOUNDRIES
}

\author{
Mile B. Djurdjevic * \\ Nemak Linz GmbH, Zeppelinstrasse 24,4030 Linz Austria \\ Received 01.07.2021 \\ Accepted 06.10.2021
}

\begin{abstract}
This paper is devoted to the memory of Professor Ljubomir Nedeljkovic (19332020), Head of the Department of Iron and Steel Metallurgy University of Belgrade, Serbia. Assessment of the melt quality is one of the most important casting process parameters, which allowed sound production of intricated cast parts. At the present time, various devices have been applied at foundry floors to control melt quality. Thermal analysis is one of them, widely used for melt quality control in ferrous and non-ferrous casting plants. During solidification, metal and alloys released latent heat, which magnitude is dependent on the type of phases that form during the solidification process. Plotting temperature versus time data during solidification provides useful information related to the actual solidification process. The applied technique is called thermal analysis, whereas the cooling curve is the name of such a plot. The main aim of this paper is to give a short overview of the present thermal analysis application in various foundries and to indicate the future potential use of this technique.
\end{abstract}

Keywords: ferrous; non-ferrous; foundries; thermal analysis.

\section{Introduction}

Application of the thermal analysis technique in the ferrous and non-ferrous casting industry for many years has been successfully employed [1, 2]. From the beginning of $20^{\text {th }}$ century, the cooling curve analysis has been applied to determine binary phase diagrams and for fundamental metallurgical studies [3]. In using this technique, binary alloys of varying composition were studied as they cooled, and the arrest points were recorded and plotted on a temperature-composition (phase) diagram. The utilization of thermal analysis as a quality control tool in cast iron plants has been recognized for more than ninety years [4]. In the middle of $20^{\text {th }}$ century, Cibula [1] and Mondolfo [2], reported that the application of thermal analysis technique could be possible in the nonferrous metallurgy studying the development of the solidify structure from the test sample

${ }^{*}$ Corresponding author: Mile B. Djurdjevic, mile.djurdjevic@nemak.com 
firstly under laboratory conditions. In the late 1980 's, this process control technique started to be regularly used in aluminum foundries [5-10].

The procedure to get the cooling curve plot is very simple. The melt preheated to approximately $100^{\circ} \mathrm{C}$ above its liquidus temperature is poured into a thermal analysis cup made from ceramic, steel, graphite, or sand. One, two, or more thermocouples are immersed into the melt, connected to data loggers. Collected signals from thermocouples are transferred into temperatures. The representation of the temperature versus time is identified as a cooling curve and has been used to describe the solidification path of investigated alloys. Some thermally weak events, which are not visible on the cooling curve, as Figure 1 illustrates, can be detected only using its first or even second derivative curves.

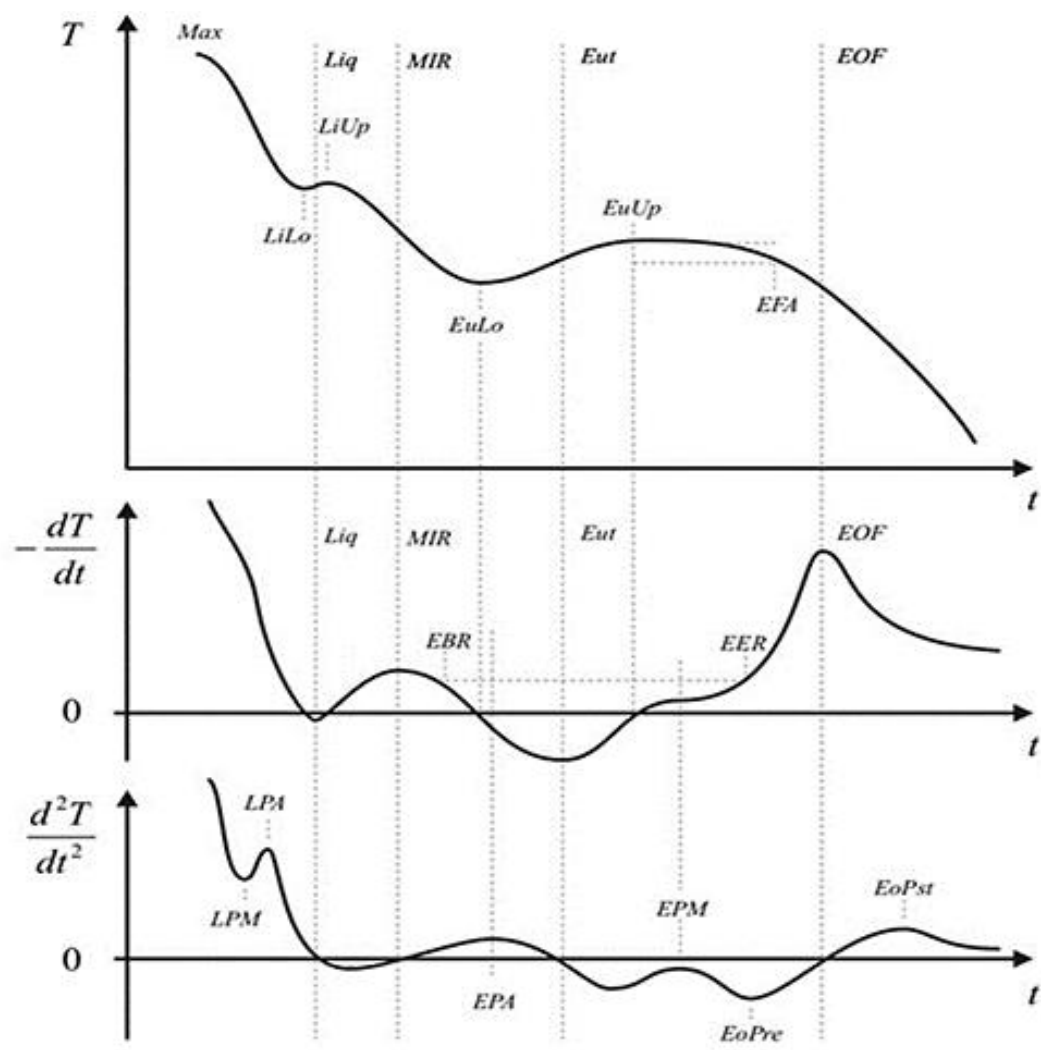

Fig. 1. Cooling (temperature/time) curve and its $1^{\text {st }}$ and $2^{\text {nd }}$ derivative [11].

Easy to handle, inexpensive, simple, accurate with high repeatability, and reproducibility are some of the properties that qualify thermal analysis to be often employed at the foundry floor $[12,13]$. The study of the effect of heat release during the solidification of various metals obviously has a long history. Today it is an accepted, and widely used tool for process control of cast parts produced using ferrous and non-ferrous alloys. Some important years in the development of thermal analysis techniques are given in Table 1. 
Table 1. Some milestones in the development of thermal analysis techniques for ferrous and non-ferrous foundries.

\begin{tabular}{ll}
\hline Years & Milestones \\
\hline $1883-1887$ & $\begin{array}{l}\text { Le Chatelier was the first scientist that recorded temperature as a } \\
\text { function of time in heating curves. } \\
\text { G. Tamman introduced the term thermal analysis. Due to the direct } \\
\text { correlation between transformation temperature and composition, } \\
\text { thermal analysis has been used extensively to build phase diagrams. }\end{array}$ \\
$1930 \mathrm{~s}$ & $\begin{array}{l}\text { Started application of the thermal analysis to cast iron foundries. } \\
1950 \mathrm{~s}\end{array}$ \\
& $\begin{array}{l}\text { Thermal analysis has been applied under laboratory conditions for the } \\
\text { study of non-ferrous alloys. }\end{array}$ \\
& $\begin{array}{l}\text { L. Bäckerud and D. Sparkman start to apply the first and second } \\
\text { derivatives in the cooling curve analysis for more accurate } \\
\text { determination of characteristic solidification events. }\end{array}$ \\
$1980 \mathrm{~s}$ & $\begin{array}{l}\text { Industrial application of thermal analysis as a standard tool in the } \\
\text { aluminum industry. } \\
\text { A significant update in the analysis of the cooling curve achieved } \\
\text { (Dendrite Coherency Point/Temperature, Rigidity Temperature, } \\
\text { fraction solid, Latent Heat) }\end{array}$ \\
\hline
\end{tabular}

A comprehensive understanding of melt quality control is one of the major priorities for foundry production and quality engineers to be able to produce sound cast parts. Being capable in advance to recognize that treated melt could potentially cause formation of the defect(s) in the cast part, one can reduce costly downtime and scraps levels. Thermal analysis has such abilities and therefore has significant advantages over its post-process counterparts which are often destructive in nature. Currently, different thermal analysis techniques as well as commercial equipment are used worldwide at the foundry floor monitoring the melt quality. This paper is going to give some basic applications of thermal analysis in the iron, steel, and aluminum foundries.

\section{Application of thermal analysis in the cast iron foundries}

As Table 1 shows, the application of the cooling curve analysis at the cast iron foundries started in $1930^{\text {st }}$. Over the years, the cooling curve analysis has become a powerful tool for the cast iron melt quality control. Nowadays, this technique is capable of determining Carbon Equivalent (CE), the evaluation of inoculation, the prediction of eutectic structure, the prediction of graphite shape, the estimated shrinkage volume, and some other properties which will be not elaborated in this paper.

\section{Carbon equivalent}

Cast iron alloys are multicomponent system, which contains various alloying elements such as Fe, C, Si, P, Mn, and others. Allowing the multicomponent iron to be treated like a binary $\mathrm{Fe}-\mathrm{C}$ alloy, the impact of other alloying elements such as $\mathrm{Si}, \mathrm{Mn}$, $\mathrm{P}, \mathrm{S}$, etc., can be expressed through the value of the Carbon Equivalent (CE). The values of Carbon Equivalent for silicon, phosphorus, manganese, and sulfur could be found in several analytical forms published in various literature $[4,14,15]$. In this paper, the 
Carbon Equivalent calculated applying equation (1) has been derived using regression analysis of experimental data taken from AMS Handbook, Casting [3]:

$$
C E=C_{C}+0.31 * C_{S i}+0.33 * C_{P}-0.027 * C_{M n}+0.40 * C_{S}
$$

where $\mathrm{C}_{\mathrm{X}}$ is the concentration of alloying element $\mathrm{X}$ expressed in wt.\%

Equation (1) is valid for the following concentration ranges: $0-4 \mathrm{wt} . \% \mathrm{Si} ; 0-0.7$ wt. $\% \mathrm{P} ; 0-1.5$ wt. $\% \mathrm{Mn}$ and $0-0.2$ wt. $\% \mathrm{~S}$.

Applying the Carbon Equivalent and multiple regression analysis the liquidus temperature of cast iron alloys can be calculated using equation (2):

$$
T L\left({ }^{\circ} \mathrm{C}\right)=1623.60-112.3 * C E
$$

Additionally, knowing the liquidus temperature of cast iron, the following analytical expression can be derived for Carbon Equivalent:

$$
C E=14.45-0.0089 * T L
$$

and graphically presented in Figure 2 .

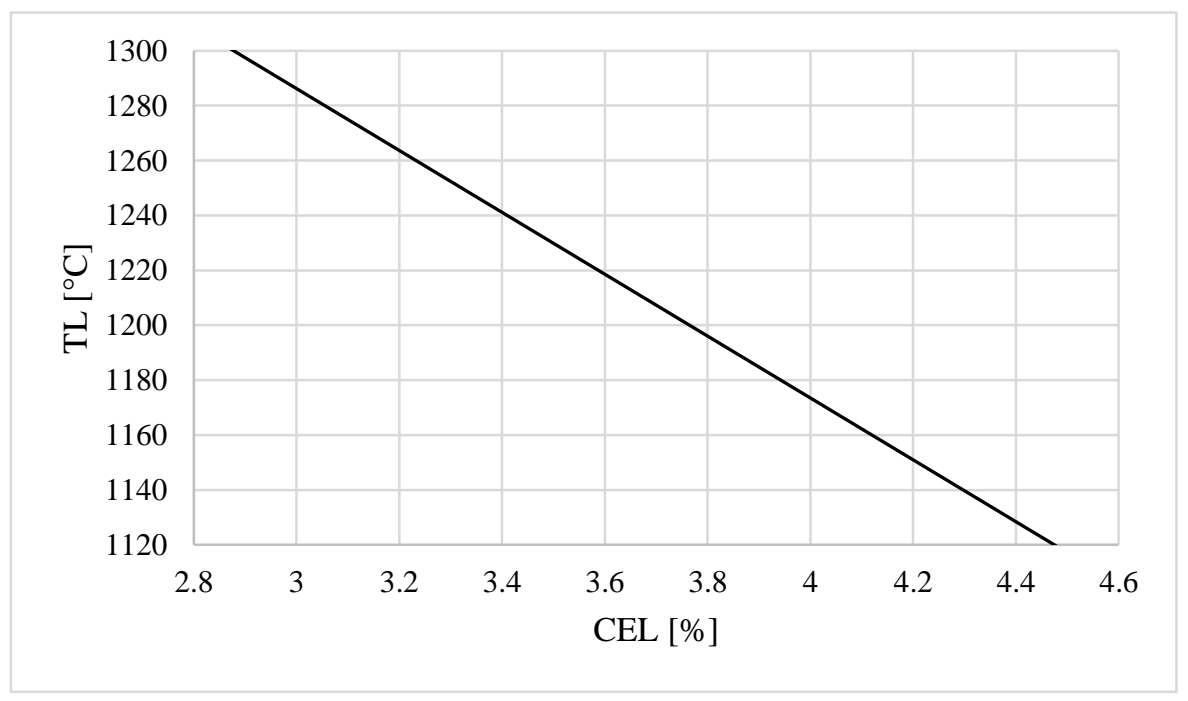

Fig. 2. Graphical relation between CE and TL [14].

\section{Evaluation of inoculation}

In cast iron foundries, thermal analysis is often used to evaluate the efficiency of added inoculant into the melt by measuring the value of eutectic undercooling $[11,16]$. In a nodular iron melt, a non-inoculated curve is characterized by having the eutectic temperature as represented in Figure 3a (lower curve-not inoculated), often without any recalescence. Added inoculant into iron melt will change the shape of the cooling curve (curve gain recalescence caused by release latent heat during graphite solidification) documented in the higher eutectic temperature, as Figures $3 \mathrm{a}$ and $3 \mathrm{~b}$ show. The melt with a higher inoculation content (upper light gray curve - good inoculated in Figure 3b) 
indicates a microstructure with higher particle density than the one with lower inoculation potential (lower dark curve in Figure 3b).

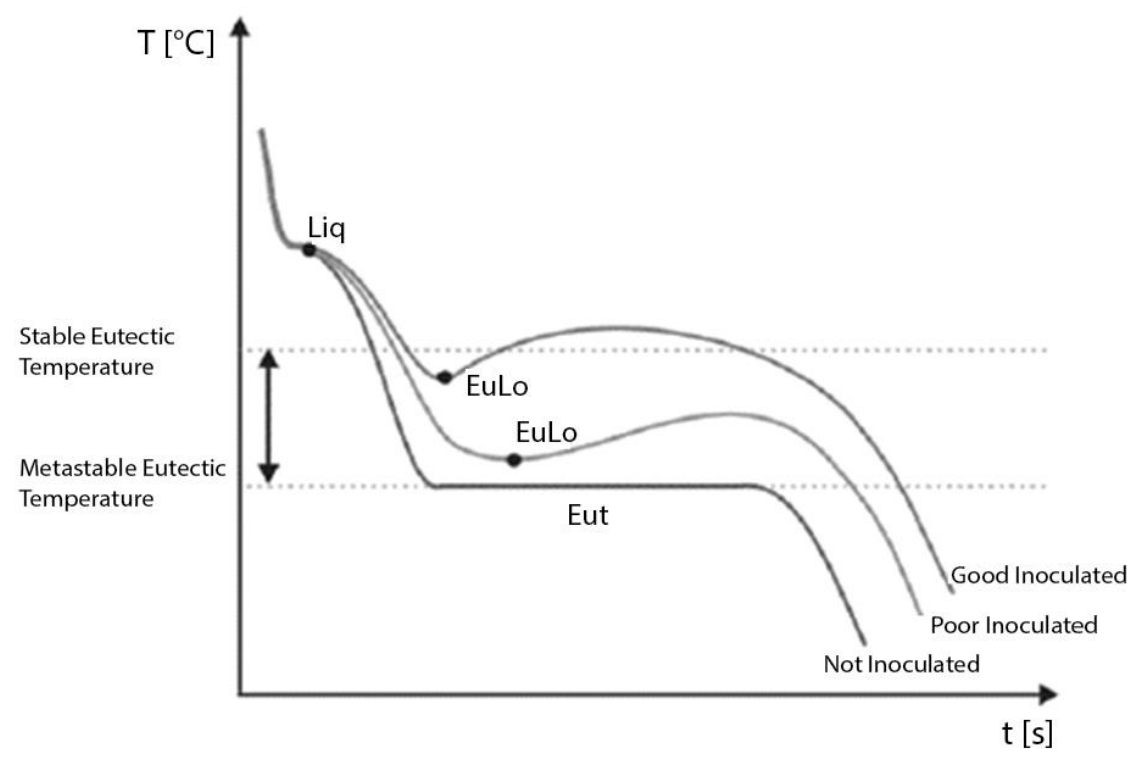

a)

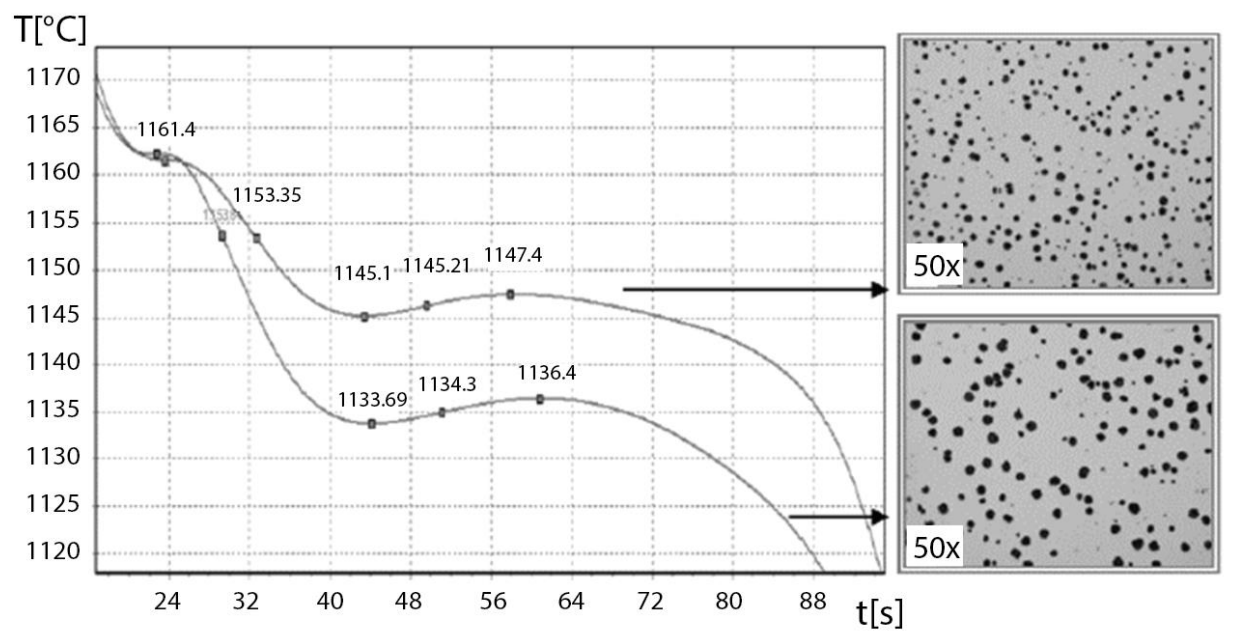

b)

Fig. 3. a) Illustration of the melts inoculation influence in the cooling curves; b) real cooling curve display showing the difference between a cooling curve with low inoculation (lower dark curve) and with high inoculation (upper light gray curve) state and respective micrographs [16]. 


\section{Prediction of graphite shape}

Early work from Lopper et.al. [17] as well as from Bäckerud [5] indicated that thermal analysis data could be actively used to control the nucleation, growth, and final graphite structure during manufacturing. The differences in the shape of the cooling curves between lamellar, compacted, and nodular graphite cast iron are demonstrated in Figure 4.

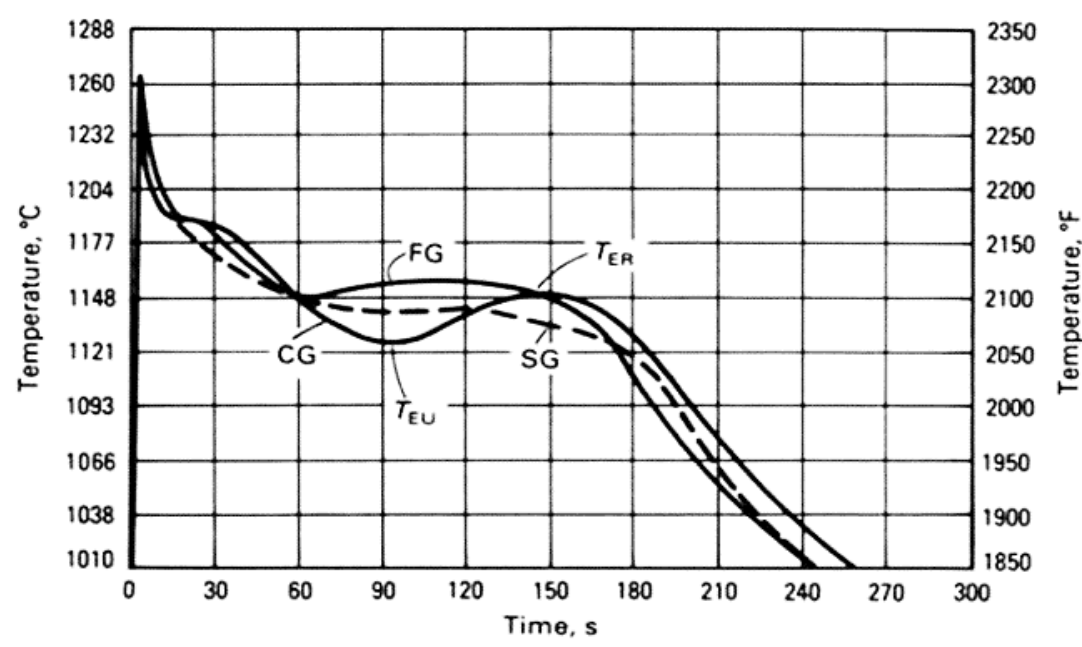

Fig. 4. Cooling curves for hypoeutectic cast iron, showing the differences in the curves for different graphite shapes (FG-lamellar graphite; $C G$-compacted graphite; $S G$ -

Nodular graphite). $T_{\text {eu }}$ and $T_{\text {er }}$ represent the low and upper eutectic temperature respectively in the compacted graphite curve [18].

\section{Prediction of eutectic structure}

Figure 5, illustrates application of the thermal analysis in the cast iron for the estimation of whether the eutectic structure during solidification will solidify as gray (stable) or white (metastable). In the case when both eutectic solidification temperatures (start and end) are above metastable temperature, $\mathrm{T}_{\text {met }}$, the iron solidifies without carbides as a gray iron (Fig. 5a). When the end of solidification is beneath $\mathrm{T}_{\text {met }}$, as Figure $5 \mathrm{~b}$ shows, then iron solidify as a mixture of gray and white iron (also known as mottled iron). The iron solidifies as a white when both start and end solidification temperature are bellow Tmet, as Figure 5c illustrate. Due to the effect of solute build - up or depletion during solidification, the $\mathrm{T}_{\mathbf{s t}}$ and $\mathrm{T}_{\mathrm{met}}$ are not a straight line. Elements that promote the formation of carbide are rejected in the liquid, their content increases and $\mathrm{T}$ met, goes up. The opposite is true for graphite promoting elements [4]. 


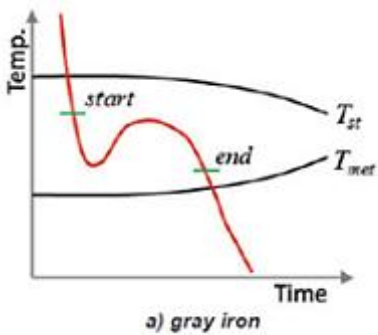

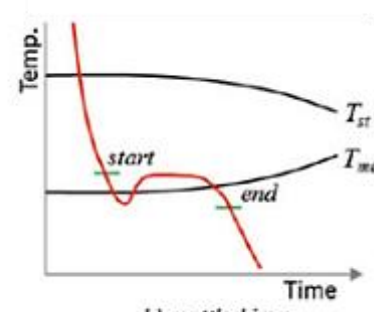

b) mottlodiron

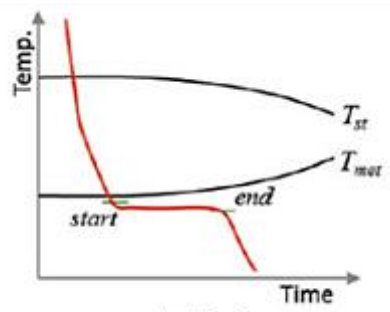

c) white iron

Fig. 5. An interpretation of cooling curves to predict stable or metastable solidification of iron [4].

Estimate shrinkage volume

Figure 6, shows the relationship between carbon equivalent and the variation in the shrinkage volume of cast iron alloys [19].

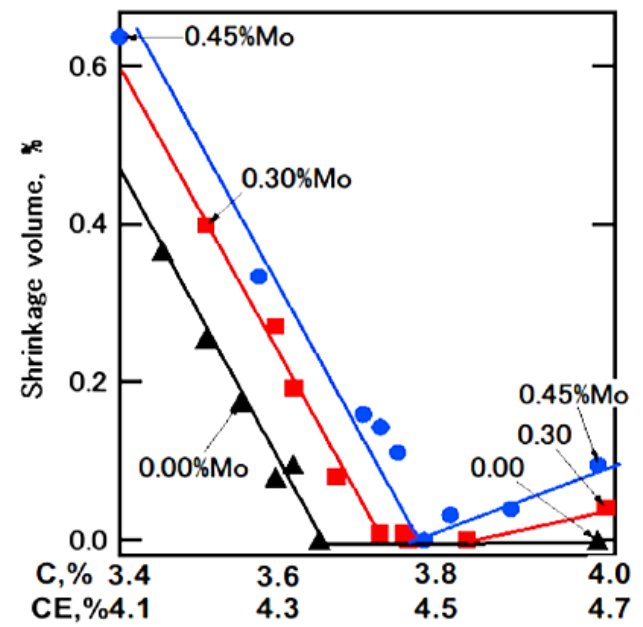

Fig. 6. Relationship between Carbon Equivalent $(C E=C+(1 / 3)$ Si) and the variation in the shrinkage volume.

According to Figure 6 [19], it is obvious that minimal shrinkage volume occurs near eutectic point for the given chemical composition. Using thermal analysis technique, the measured liquidus temperature can be used to calculate Carbon Equivalent. Based on the known Carbon Equivalent, the percentage of shrinkage volume for the investigated cast iron alloys can be an easy estimate.

\section{Application of thermal analysis in the steel foundry}

The exact knowledge of liquidus and solidus temperature is one of the most important preconditions for nowadays increasingly demanded rigorous control of the final steel refining and solidification processes. It is also essential for a fine tuning of their casting temperature during ladle treatment. Both liquidus and solidus temperatures are critical parameters for proper adjustment of physical and numerical modelings, 
significantly affecting the final quality of the as cast steel parts[20]. Liquidus temperatures of various steel grades are commonly determined using cooling curve analysis. The solidus temperature of any steels can also be determined by applying the thermal analysis technique (cooling curve analysis). However, in most cases the determination of the solidus temperature is extremely imprecise. The reasons for this can be summarized as follows:

- solidification cannot be completed at the equilibrium solidus temperature since solid phase contained concentration gradients.

- the sensitivity of thermocouple is reduced by precipitated solid phases causing insulation of thermocouple from sample;

- finally, the solidus temperature is moved toward the sample temperature having lagged well behind the furnace temperature causing that the cooling rate start to accelerate rapidly.

Due to all previously mentioned reasons, the steel solidus temperatures are better measured by heating curves which are, according to Pelton [21], analogous to cooling curves.

The main aim of this section is to show the application of the thermal analysis techniques in the steel foundries and to reveal how the solidus and liquidus temperatures of selected steel grades have been identified. Figure 7 illustrates the typical cooling curve of steel with its potential solidification events [22].

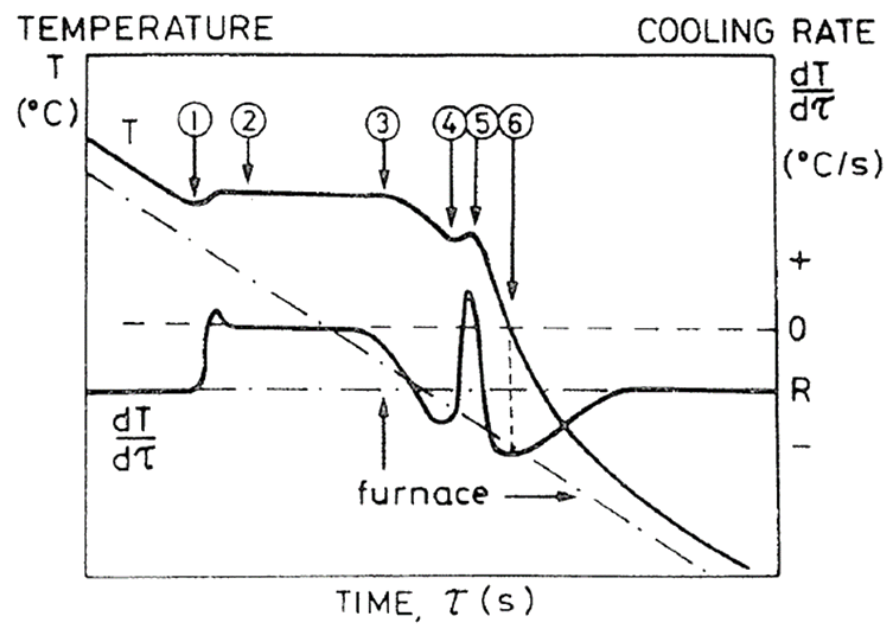

Fig. 7. Temperature-time cooling curve and its first derivative curve for selected steel grade and expected solidification events [22].

(1) Start of growth of primary (ferrite) phase

(2) Growth temperature of dendrites, used as liquidus temperature (plateau)

(3) Dendrite tips reach thermocouple in center of sample

(4) Start of secondary (peritectic) phase precipitation

(5) Maximum reaction rate for secondary phase precipitation, maximum temperature, used as temperature of formation of the secondary phase

(6) End of solidification, used as solidus temperature (minimum cooling rate)

$\mathrm{R}$ Preset cooling rate of furnace 
The low carbon steels represent the most common commercial steels. They are produced as ingots and cast ingots of all sizes. Continuous casting is also widely used for all except the steel with the highest carbon content. Carbon steels exist with carbon levels from below $0.1 \%$ to above $1.3 \%$, depending upon the required strength and hardness. For a carbon steel with following chemical compositions expressed in wt.\%: $\mathrm{C}=0.12 ; \mathrm{Si}=$ $0.27 ; \mathrm{Mn}=1.53 ; \mathrm{P}=0.010 ; \mathrm{S}=0.005 ; \mathrm{Cr}=0.02 ; \mathrm{Ni}=0.03 ; \mathrm{Mo}<0.03 ; \mathrm{Cu}=0.05 ;$ Altot $=0.029 ; \mathrm{Ce}=0.03$, and $\mathrm{N}=0.011$, its cooling and first derivative curves are given in Figure

8

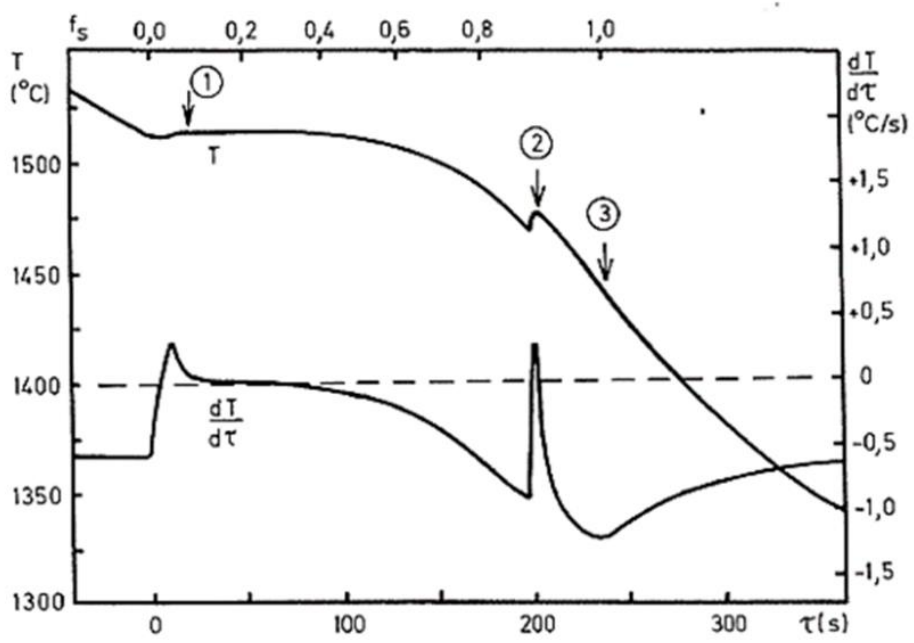

[22].

$\mathrm{R}=0,5^{\circ} \mathrm{C} / \mathrm{s}$

Fig. 8. Thermal analysis of carbon steels with its chemical compositions.

The following reactions can be recognized during carbon steels solidification:

(1) Liquidus temperature, ferritic primary phase $=1515^{\circ} \mathrm{C}$

(2) Temperature of austenite formation $=1475^{\circ} \mathrm{C}$

(3) Solidus temperature $=1410{ }^{\circ} \mathrm{C}$

Solidification range $=75^{\circ} \mathrm{C}$

Solidification time $=105 \mathrm{~s}$

$\mathrm{R}$ Preset cooling rate of furnace

Selected cooling curves for high-speed steels have been included in this paper for comparison with carbon steels. As Figure 9 illustrates [22], those steels have slightly complicated solidification paths in comparison to carbon steels. The chemical composition of this high speed steel, expressed in wt.\% was: $\mathrm{C}=0.88 ; \mathrm{Si}=0.30 ; \mathrm{Mn}=$ $0.32 ; \mathrm{P}=0.030 ; \mathrm{S}=0.017 ; \mathrm{Cr}=3.9 ; \mathrm{Ni}=0.36 ; \mathrm{Mo}=4.9 ; \mathrm{W}=6.1 ; \mathrm{Cu}=0.10 ;$ Altot $=$ $0.22 ; \mathrm{Ce}=0.30$, and $\mathrm{N}=0.036$. 


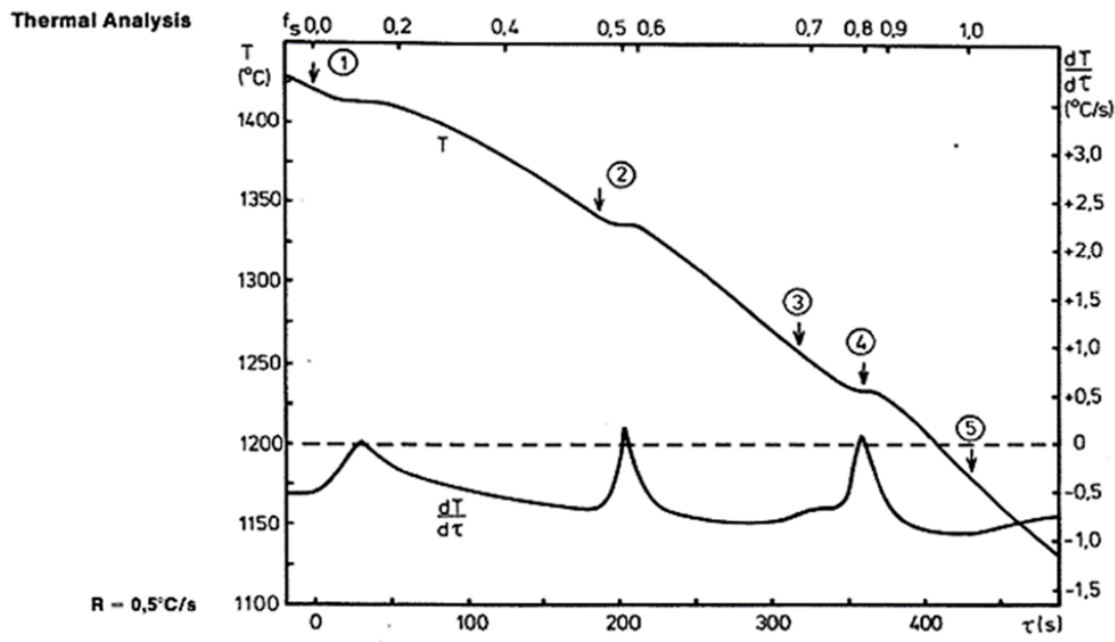

Fig. 9. Thermal analysis of high-speed steels with its chemical compositions.

The following reactions can be recognized during high speed steels solidification:

(1) Liquidus temperature, ferritic primary phase $=1423^{\circ} \mathrm{C}$

(2) Temperature of start of austenite formation, $=1342^{\circ} \mathrm{C}$

(3) Temperature of start of MC-austenite eutectic formation, $=1260{ }^{\circ} \mathrm{C}$

(4) Temperature of $\mathrm{M} 2 \mathrm{C}-$ and $\mathrm{MsC}$ austenite eutectic formation, $=1232{ }^{\circ} \mathrm{C}$

(5) Solidus temperature, $=1185^{\circ} \mathrm{C}$

Solidification range, $240{ }^{\circ} \mathrm{C}$

Solidification time, $=455 \mathrm{~s}$

\section{Thermal analysis application in the aluminum foundry}

The application of thermal analysis technique in the non-ferrous (aluminum) metallurgy started initially in laboratories at the beginning of 1950s and its commercial application at the foundry floors has been recognized in the last four decades. The thermal analysis procedure is useful for checking the microstructure of aluminum alloys before the melt is solidified. The microstructure is an important parameter in cast aluminum alloys because it has a direct impact on the mechanical properties of cast parts. For most of the cast aluminum alloys, two parameters of microstructure are of primary importance: grain size and silicon modification level. Certain parts of the cooling curve can be used to accurately predict the efficiency of grain refinement $(\mathrm{Ti}, \mathrm{B}, \mathrm{Zr}, \ldots)$ and modification $(\mathrm{Sr}, \mathrm{Na}, \mathrm{Sb}, \ldots)$ additions into the aluminum melt. Before that, let see how looks like a cooling curve of one commercial aluminum alloy and its solidification path.

A representative cooling curve of the AlSi10Cu0.3Mg0.4 alloy with its first derivative curve and typical solidification temperatures of precipitated phases obtained using a center thermocouple $\left(\mathrm{T}_{\mathrm{C}}\right)$ is presented in Figure 10. 


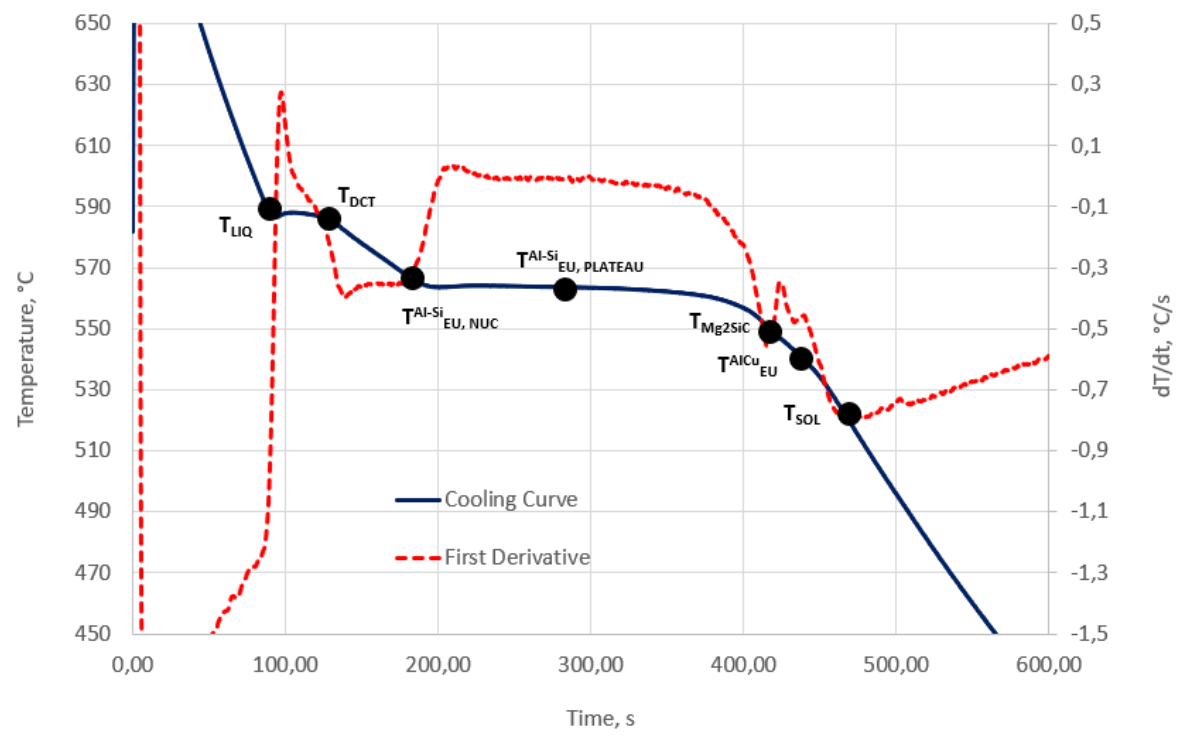

Fig. 10. The cooling and first derivatives curves of the AlSilOCu0.3MgO.4 alloy.

Solidification of any Aluminum alloys starts at the liquidus temperature ( $\left.\mathrm{T}_{\mathrm{LIQ}}\right)$ with the formation of small solid pieces of $\alpha$-Al nucleus. Further cooling of the melt, sometimes supported with the addition of some foreign particles (grain refiners), allows the formation of millions of other nuclei, which start to grow with a dendritic form. At a certain temperature below liquidus, these dendrites start to touch each other and form the solid skeleton in the residual melt. The temperature at which this happens is called dendrite coherency $\left(\mathrm{T}_{\mathrm{DCT}}\right)$. Cooling down to a lower temperature, the primary AlSi eutectic phase starts to precipitate ( $\mathrm{T}^{\mathrm{AlSi}}$ EU or so called AlSi plateau eutectic temperature). The presence of other alloying elements such as $\mathrm{Cu}, \mathrm{Mg}, \mathrm{Fe}$ and especially $\mathrm{Sr}$ and $\mathrm{Na}$ depress the start of precipitation significantly towards a lower temperature. Close to the end of solidification in some alloys with a minimum $\mathrm{Cu}$ concentration, Copper rich phases start to precipitate $\left(\mathrm{T}^{\mathrm{ALCu}}{ }_{\mathrm{EU}}\right)$. The temperature at which the last drop of liquid is transformed into solid is called solidus temperature $\left(\mathrm{T}_{\mathrm{SOL}}\right)$. In aluminum alloys with a certain concentration of $\mathrm{Mg}$, its corresponding intermetallics also start to precipitate (e.g., $\left.\mathrm{T}_{\mathrm{Mg} 2 \mathrm{Si}}\right)$. 
Assessment efficiency of added grain refiner and modifier into aluminum melt

Aluminum alloys without addition of grain refinement, form coarse, equiaxed and columnar crystals structure during solidification. In the aluminum foundry industry several methods have been applied (increasing cooling rate, the dynamic techniques like vibration and stirring) to grain refined primary $\alpha$-aluminum structure [23].

Addition of grain refiners (AlTi and AlTiB) is at the present the most common method used in the aluminum casting industry. The cooling curve profile during solidification of aluminum cast alloys gives a good indication of the number of nuclei present in the melt. The little primary undercooling as indicated in Figure 11a by blue line means that in the melt there are a great number of nuclei. Fewer number of nuclei in the melt will cause larger undercooling (illustrated in Figure $11 \mathrm{~b}$ by the red line).

Undercooling parameter $\Delta \mathrm{T}\left(\Delta \mathrm{T}=\mathrm{T}_{\mathrm{MAX}}-\mathrm{T}_{\mathrm{MIN}}\right)$ from the cooling curve has been routinely used at foundry floor for quality process control giving quick information related to efficiency of grain refiners added into aluminum melt. Smaller undercooling $(\Delta \mathrm{T})$ means higher potency of master alloys leading to smaller casting grains in solidify structure.

Aluminum hypoeutectic alloys during solidification beside primary $\alpha$-Al phase characterized the presence of primary needle like Al-Si eutectic structure. In order to increase their properties, the as cast silicon structure of these alloys have been modified by adding different amount of modifiers ( $\mathrm{Sr}$ or $\mathrm{Na}$ ). Strontium has been widely used in aluminum casting plant as a modifier of hypoeutectic aluminum-silicon cast alloys. The addition of Sr changes coarse Silicon structure to fine fibrous improving mechanical and metallurgical properties of these alloys. For each Al-Si alloy there is an optimal amount of Strontium additions that can be controlled by using cooling curve analysis. Figure 11b, shows the effect of modification on the aluminum-silicon eutectic plateau temperature (TAl-Si). The depression of the aluminum-silicon eutectic plateau temperature $(\Delta \mathrm{T})$ represents the temperature difference between the unmodified and modified aluminumsilicon eutectic growth temperatures [23]. The larger the magnitude of $\Delta \mathrm{T}$ the higher the level of modification (it means the smaller size of silicon particles). The advantage of Thermal Analysis in comparison to classical chemical analysis is, in fact that the cooling curve measured the only impact of active strontium. It means that only free strontium that is not bonded in some intermetallics can be used to change silicon morphology. 

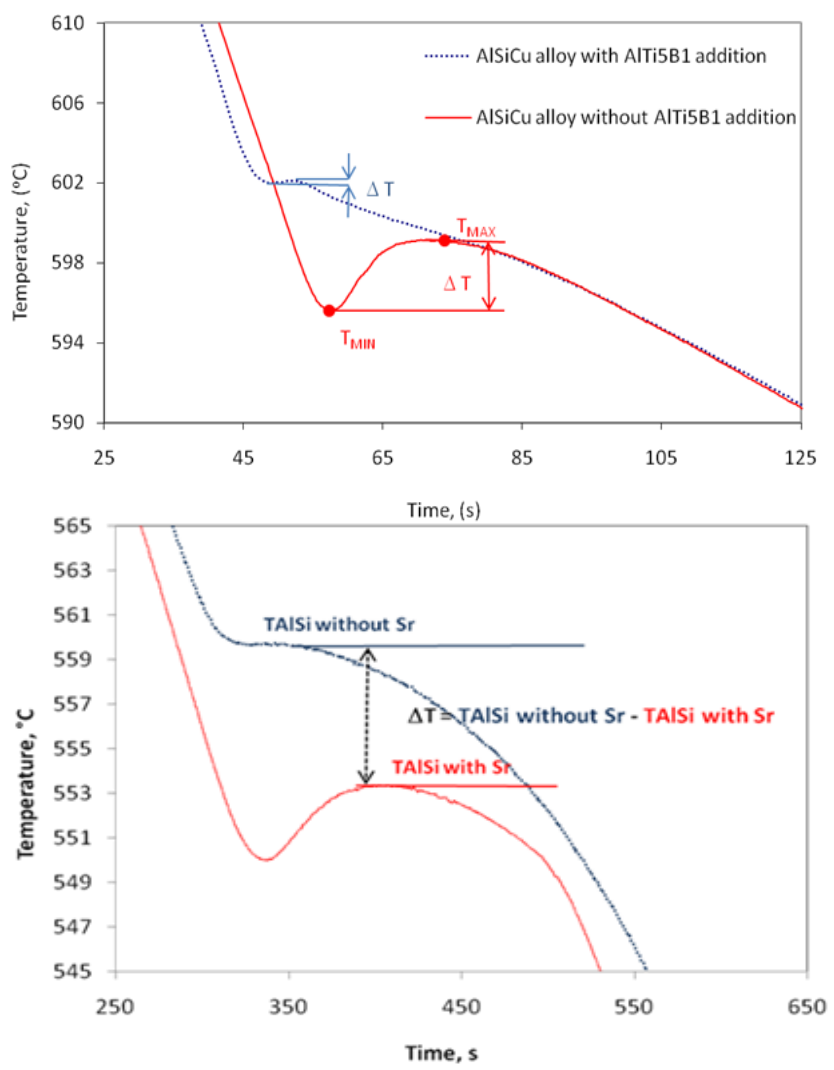

Fig. 11. Part of the cooling curve related to: a) the primary solidification of aluminum alloys and b) Al-Si eutectic region.

\section{Discussion and conclusion}

This paper gives some overview about thermal analysis application in ferrous and non-ferrous casting metallurgy. It is obvious that thermal analysis technique has been used routinely for assessment the Carbon Equivalent, efficiency of inoculant additions or determination of liquidus and other characteristic solidification temperatures by various melts. Many others parameters such as fraction solid distribution, latent heat of solidification, terminal freezing range under equilibrium and non-equilibrium conditions, dendrite coherence and rigidity temperatures can be also determined using cooling curve analysis.

Modern casting industries which require more application of various simulation software packages open some extra field for thermal analysis. The interest in simulation applied in the casting industry has extended significantly in the last few decades. Three main reasons are responsible for that: (i) the necessity to improve productivity and quality of cast products (ii) to speed up the design process and (iii) to investigate the influence of different process parameters without the need of expensive experimental trials. The precision of casting simulation depends mostly on the quality of the existing physical and 
thermophysical material data stored in the software's database. Existing databases now applied by commercial simulation software packages for the ferrous and non-ferrous casting industry generally come with material properties for only selected standard alloys. In the case of more sophisticated alloys with divergent chemical compositions, refinement and/or modification treatments, thermal analysis could be a very useful tool to collect the missing parameters or even to get more accurate thermophysical data for investigated alloys.

The data collected using cooling curve analysis should be used in currently applied simulation software to improve accuracy of simulation. Intricate cast parts contain different cross section thicknesses that solidified under different cooling rates, which in turn affect as-cast structure. In order to be able to produce such complex cast products it is necessary a deeper understanding of the melt flow through semi solid cast structure of cast parts. Thermal analysis in synergy with simulation software packages is a useful tool to help gauge the lack of knowledge regarding the understanding of feeding mechanisms during the solidification of ferrous and non-ferrous cast alloys. The thermal analysis apparatus is capable to collect the cooling curves that solidified under various process parameters and calculating all characteristic solidification temperatures. Recorded data can be used as an input database for simulation in order to more accurately predict the quality of very complex cast parts. The data necessary for the simulation of casting processes can be gathered either using experiments or calculated using commercial simulation software packages. Both approaches have advantages and disadvantages and need to be used on a comparative basis. Experiments are expensive, time consuming but sometimes the only possible source for thermo physical and physical properties. In contrary to them, simulation is very fast, can be repeated many times, and provide consistent results. The industrial interest is, of course, to be able to make simulation and optimization based on more realistic database in order to be able to predict the quality of very complex cast parts. Thermal analysis has such opportunity and has to be used more often in providing simulation engineers with all necessary data for simulation, of course in synergy with commercial software packages.

\section{Literature:}

[1] A.Cibula: J Ins Metals, (1949) 312.

[2] P.B. Crossley, L.F. Mondolfo: Modern Casting, 49 (1966) 53-64.

[3] AMS Handbook, Vol. 3., Alloy Phase Diagram, AMS International, 1992 ISBN 0-87170-377-7, Editor Hugh Baker, pp.15-17.

[4] D. M. Stefanescu: Int J Metalcast, 9 (2015) 7-22.

[5] L. Bäckerud et al. "Solidification Characteristics of Aluminum Alloys" Volume 1 to 3, AFS/SKANALUMINIUM, 1986, Oslo.

[6] B. R. Krohn, “Thermal analysis: Metallurgical Thumbprinting”, Modern Casting, March 1985, pp.1-7.

[7] J. E. Gruzleski ,B. M. Closset, "The treatment of liquid aluminum-silicon alloys" American Foundryman's Society, Inc. Des Plaines, 1990 Illinois, USA.

[8] N. Tenekedjiev, H. Mulazimoglu, B. Closset and J. Gruzleski, "Microstructures and Thermal Analysis of Strontium-Treated Aluminum-Silicon Alloys", American Foundryman's Society, Inc. Des Plaines, Illinois, USA, 1995, p. 40-41.

[9] L. Ananthanarayanan, and J. E. Gruzleski: AFS Transactions, 141 (1992) 383-391.

[10] D. A. Sparkman: AFS Transactions, 119 (2011) 413-419. 
https://www.solutionsfonderie.com/wp-content/uploads/2016/01/Sparkman2011-AFS-Paper.pdf

[11] W. Baumgart, "Untersuchung des Phasenübergangs von flüssig nach fest am tertiären System Fe-C-Si unter Nichtgleichgewichtsbedingungen,” Lehrstuhl für das gesamte Gießereiwesen und Gießerei-Institut der RWTH Aachen, 2013, Aachen - Germany.

[12] H. Beumler, A. Hammerstad, B. Wieting, R DasGupta: AFS Transaction, 54 (1988) 1-12.

[13] M. Garat, G. Laslaz, S. Jacob, P. Meyer, P. H. Guerin, R. Adam: AFS Transactions, 100 (1992): 821-832.

[14] L. Wang, S. Shivkumar: Journal of Materials Science, 30 (1995) 1584-1594.

[15] Heraeus Electro-Nite International, Thermal analysis of cast iron, https://www.heraeus.com/media/media/hen/media_hen/products_hen/iron/therm al_analysis_of_cast_iron.pdf, Accesed 11, 2021.

[16] W.F. Smith: Structure and properties of engineering alloys, 2nd edition ed., McGraw Hill International, 1993, p. 340.

[17] W. Baumgart, J. Cunha and V. Anjos, "Het enten van gietijzer," Gietwerk Perspectief Magazine - No.5, (2010) 5-12.

[18] C. R. Loper, R. W. Heine, A. Shah: AFS Transactions, 75 (1967) 541.

[19] BDG, Gusseisen mit Kugelgraphit: Herstellung - Eigenschaften - Anwendung, Düsseldorf: Bundesverband der Deutschen Gießerei-Industrie, 2007, p. 2.

[20] S. Koriyama, T Kanno, Y. Iwami, I. Kang: International Journal of Metalcasting, 14 (2020) 1-8.

[21] K. Gryc, B. Smetana, M. Tkadleckova, M. Zaludova, L. Sochna, K. Michalek and L. Valek, "Comparison of thermal analysis results with theoretical determination of solidus and liquidus temperatures for specific steel grade", Metal 2013, 15-17 May 2013, Brno, Czech Republic, pp. 1- 6.

[22] A. D. Pelton, "Physical Metallurgy 4th edition, 1996, ISBN 978-0-444-89875-3.

[23] G. Grünbaum et. al., "A guide to the solidification of steels", Jernkontoret Stockholm 1977, ISBN 91-7260-156-6, pp. 1-11.

[24] M. B. Djurdjevic; "Present and future application of the thermal analysis in aluminum casting industry", First Metallurgical and Materials Engineering Congress of South East Europe, 2013, Belgrade, Proceedings and book of abstracts, May 23-25 2013, Belgrade, Serbia, pp.47-62.

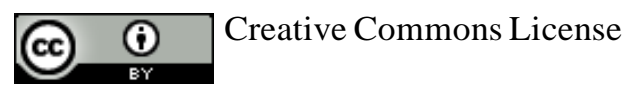

This work is licensed under a Creative Commons Attribution 4.0 International License. 